\title{
Assessing Sustainable Urban Mobility Policies in the Mediterranean Tourism Destinations Through Multi-Criteria Decision-Making Models
}

\author{
Eleni Farmaki, Maria Aryblia, Stavroula Tournaki, and Theocharis Tsoutsos
}

\begin{abstract}
This chapter presents the assessment of 11 sustainable urban mobility measures according to 10 criteria for European medium-sized touristic cities, using multi-criteria decision-making. The study includes the viewpoint of six different European stakeholder groups, identifying their interests and comparing their ranking on appropriate mobility measures. It was found that the majority of stakeholders give the highest priority to the wellbeing of local communities and the quality of life, despite the economic implications of services and the potential impact on incoming tourism. Mostly they emphasise on at least two out of five criteria categories: Society and Environment or Society and Mobility. Tourism stakeholders showed a high preference for environmental criteria, demonstrating the continuously raising awareness on the links of tourism and environment. "Mobility management and travel plans" policy was the most popular policy amongst all groups, indicating that the provision of information, personalised plans, and smart applications can increase the use of sustainable mobility modes and have a significant positive impact in all examined categories. Overall, the multi-criteria analysis performed in this study can be a valuable tool for decision-makers during the shaping of future policies for sustainable mobility in urban tourist destinations, considering numerous parameters and stakeholders' viewpoints. Moreover, it can be further developed and adapted to specific needs.
\end{abstract}

Keywords Sustainable mobility solutions · Multi-criteria analysis •

Decision-making $\cdot$ Sustainable urban planning

\section{Abbreviations}

MAMCA Multi-actor multi-criteria analysis

MCDA Multi-criteria decision analysis

E. Farmaki · M. Aryblia · S. Tournaki · T. Tsoutsos (凶)

Renewable and Sustainable Energy Systems Lab, School of Chemical and Environmental

Engineering, Technical University of Crete, Chania, Greece

e-mail: theocharis.tsoutsos@enveng.tuc.gr

T. Tsoutsos (ed.), Sustainable Mobility for Island Destinations,

https://doi.org/10.1007/978-3-030-73715-3_2 
SUMP Sustainable urban mobility plan

\section{Introduction}

Several studies stress the impact of tourism on local environmental and traffic conditions, resulting in significant air pollution, energy consumption (Page \& Gue, 2016; Aguiló et al., 2012), congestion (Saenz-de-miera \& Rosselló, 2012), and road accidents; to alleviate these impacts, tourist destinations turn to the alternative transport modes, such as public transport, shared vehicles, and high-quality services for visitors. (Gronau, 2017). The incorporation of the tourism aspect in the planning process will allow tourist destinations to better address the fluctuation of demand and needs.

Sustainable Urban Mobility Plans (SUMPs) are designed, developed, and implemented having as central core the societies, not the transportation infrastructure, aiming to provide a better quality of life within the urban locations. Integration, participation, and evaluation processes are amongst the basic principles on which a city can build its unique SUMP. Urban planners and decision-makers are often facing numerous challenges, trying to integrate and gather previous knowledge, existing successful practices, innovation, and new technology actions. The complexity level of a decision-maker before the implementation of a SUMP is shown in Fig. 1, grouped into four main steps:

1. Preparation and analysis,

2. Strategy development,

3. Measure planning, and

4. Implementation and monitoring (European Commission 2019).

Taking into account the rapid developments, the assessment of sustainable mobility strategies is proven to be a complicated task, as it requires the examination and incorporation of a wide variety of factors (environmental, social, technical, and financial). A variety of techniques provide a flexible approach to deal with a wide range of factors, thus providing significant assistance in decision-making, such as Multi-Criteria Decision Analysis (MCDA) method.

Several studies have incorporated the interests of relevant stakeholders in the multi-criteria assessment, focussing on sectors of planning, technical infrastructure. Tsoutsos et al. (2009) investigated the sustainable energy planning for the island of Crete using the multi-criteria analysis to assist the competent decision-makers in defining the most suitable alternatives taking into consideration economical, technical, environmental, and social criteria (Tsoutsos et al., 2009).

Macharis et al. (2010) developed the Multi-Actor Multi-Criteria Analysis (MAMCA) methodology to evaluate transport projects (Tsoutsos et al., 2009), which was applied to evaluate ten policies, in terms of mobility and logistics, in the "Flanders in Action Process". The preferences of 11 stakeholder groups were represented 


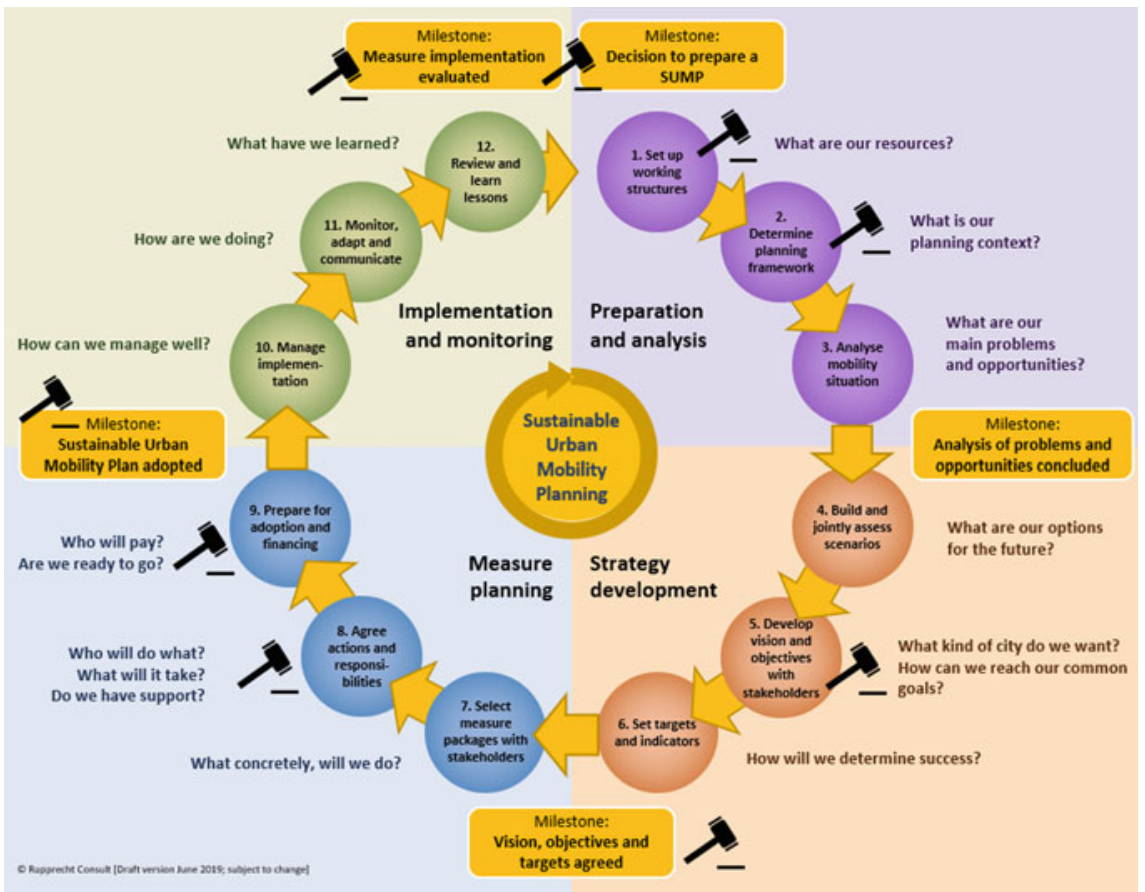

Fig. 1 The main steps of Sustainable Urban Mobility Plans (European Commission, 2019)

by evaluating pre-defined criteria. The most preferred policies were the stimulation of multimodal transport, the coordination of measures, and spatial planning.

Sun et al. (2015) evaluated six low-carbon transport policies in a Chinese city: tax and pricing adjustments, multi-operation mechanisms, environmental campaign, traffic demand management, and state funding and subsidies. Several stakeholders' groups were engaged in the process, and although their preferences varied, most groups considered state funding and subsidies as the most effective policy, along with traffic demand management.

Bulckaen et al. (2015) proposed a framework for ranking three small-scale urban and regional mobility projects that include policies different in theme, country, and objectives. The framework was a combination of MCDA to assess the sustainability of the projects and MAMCA to assess stakeholder preferences. The PROMETHEE method with 16 criteria was used, grouped under the three pillars of sustainability.

The main aims of this study are as follows:

- to offer a methodology to support the prioritising of existing mobility policies by the policymakers and

- to incorporate the various influence factors into the assessment of sustainable mobility policies for medium-sized, urban touristic areas of the Mediterranean.

- Environmental aspects (pollution, energy), 
- Mobility issues (traffic conditions, transport infrastructure),

- Tourism flows,

- Financial factors (finance of service, local economy), and

- Society factors (safety, accessibility, users' satisfaction).

\section{Methodology}

The authors studied the influence factors in the assessment of sustainable mobility policies for medium-sized, urban touristic Mediterranean areas. A total of 11 sustainable mobility policies (actions) have been evaluated according to 10 specific criteria, in five main categories: Environment, Mobility, Tourism, Economy, and Society. The criteria were evaluated by six European stakeholder groups, according to their significance in the selection of appropriate policies. Their ranking provided valuable input for the calculation of corresponding weights for the analysis. The stakeholders were selected from the Horizon 2020 CIVITAS DESTINATIONS project network.

\subsection{The PROMETHEE-Approach}

The MCDA method employed was PROMETHEE, which ranks a set of $\mathrm{n}$ alternatives $a_{i}(i=1,2, \ldots, n)$ based on a $k$ criteria $g_{j}(j=1,2, \ldots, k)$. Figure 2 presents the main steps of the PROMETHEE method, as followed in this study.

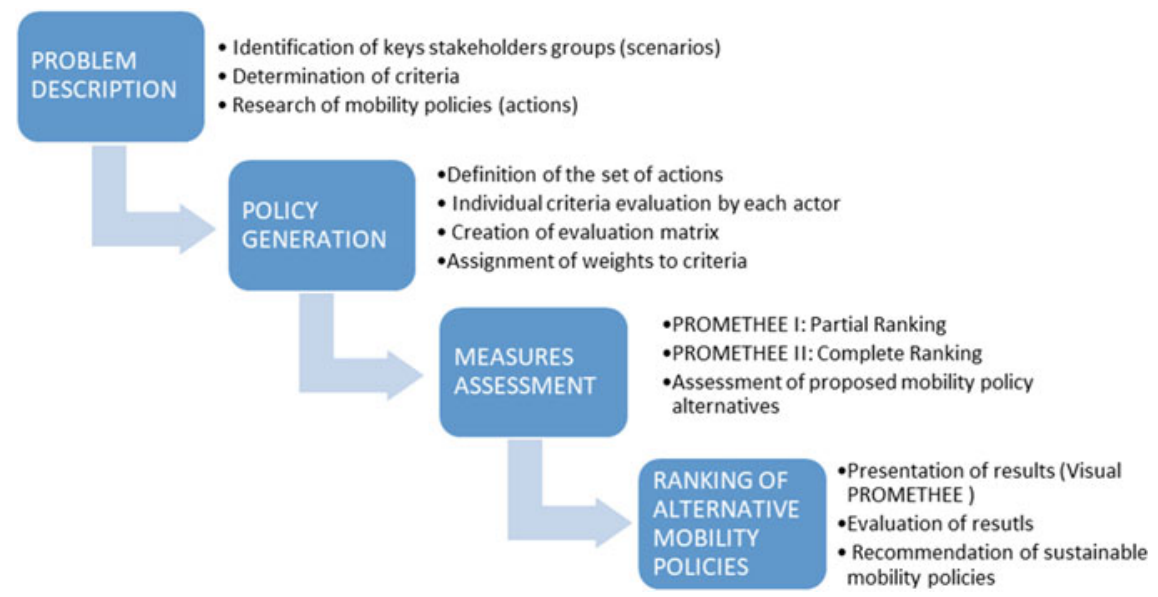

Fig. 2 Assessment Methodology of sustainable mobility policies 


\subsection{Sustainable Mobility Policies Alternatives}

The selection of the specific strategies was based on the outcomes of related projects evaluating sustainable mobility policies. The goal was to assess a wide variety of mobility policies suitable for medium-sized tourist urban areas (Letnik et al., 2018), aiming to include eco-friendly transport solutions, current trends that promote social cohesion, recent technologies, solutions for infrastructure and equipment, "soft" policies, and tourist-oriented services. The selection of policies was also highly influenced by the sustainable mobility actions carried out in the frame of the CIVITAS DESTINATIONS project in the city of Rethymno. The selected mobility policies were adjusted to the specific objectives of the study, including most transport modes: car, public transport, and active mobility (cycling, walking).

The examined alternative sustainable mobility policies were as follows:

- Sustainable Urban Mobility and Logistic Plans,

- Smart metering systems,

- Increased traffic safety and security_Eco and safe driving training,

- Mobility plans for school communities,

- Attractive and accessible public spaces,

- Shared mobility services,

- E-charging infrastructures and e-vehicles in public fleets,

- Mobility management and travel plans,

- Behavioural change and informative actions,

- Low emission zones and parking management, and

- Improved and accessible PT services for tourists and residents.

\subsection{Sustainable Mobility Criteria}

Criteria were selected based on relevant researches and frameworks complied, to assess transport policies (Awasthi et al., 2018). The sustainable mobility measures (actions) were evaluated according to specific criteria, covering five main categories: Environment, Mobility, Tourism, Economy, and Society (Table 1).

\subsection{Actors Involved in Sustainable Mobility Planning}

Groups of stakeholders were mapped at first, assuring the inclusion of all key categories, in terms of demand and offer (i.e. users/operators); public and private experts (i.e. academics/consultants); and governance and non-profit organisations, according to the pillars of sustainable development (economy, environment, and society). The additional element in this specific study is the involvement of tourism actors, a 
Table 1 Description of evaluation criteria

\begin{tabular}{|c|c|c|}
\hline \multirow{3}{*}{$\begin{array}{l}\text { Category } \\
\text { Environment }\end{array}$} & \multicolumn{2}{|l|}{ Criterion } \\
\hline & Energy (ENE) & $\begin{array}{l}\text { Reduction of energy/ fuel consumption } \\
\text { and the share of conventional fuel in the } \\
\text { implementation area }\end{array}$ \\
\hline & Environmental pollution (ENV) & $\begin{array}{l}\text { Reduction of average GHG emissions and } \\
\text { noise levels in the implementation area }\end{array}$ \\
\hline \multirow[t]{2}{*}{ Mobility } & Traffic conditions (TRC) & $\begin{array}{l}\text { Modal share shift towards alternative } \\
\text { transport of the target group involved and } \\
\text { Traffic flow improved in the examined } \\
\text { area }\end{array}$ \\
\hline & Transport infrastructure (TRI) & $\begin{array}{l}\text { Level of intermodal integration of } \\
\text { transport services, along with existing } \\
\text { infrastructure }\end{array}$ \\
\hline Tourism & Tourist flow (TOU) & $\begin{array}{l}\text { Increased share of tourists using transport } \\
\text { services, No. of incoming tourists, and } \\
\text { GDP generated by tourism }\end{array}$ \\
\hline \multirow[t]{2}{*}{ Economy } & Service finance (SEF) & $\begin{array}{l}\text { Cost of new services and infrastructure, } \\
\text { including capital costs and maintenance }\end{array}$ \\
\hline & Local economy (LOE) & $\begin{array}{l}\text { Level of the increased affordability of } \\
\text { public transport services for the users, } \\
\text { level of financial gain by new services, } \\
\text { and infrastructure for operators }\end{array}$ \\
\hline \multirow[t]{3}{*}{ Society } & Safety (SAF) & $\begin{array}{l}\text { Level of perceived road safety and } \\
\text { security amongst target groups involved } \\
\text { and reduction of No. of road incidents }\end{array}$ \\
\hline & Users Satisfaction (USS) & $\begin{array}{l}\text { Level of satisfaction and acceptance of } \\
\text { the mobility policies amongst the target } \\
\text { groups involved }\end{array}$ \\
\hline & Accessibility (ACC) & $\begin{array}{l}\text { Level of accessibility of transport } \\
\text { services and infrastructure and perception } \\
\text { of accessibility amongst users }\end{array}$ \\
\hline
\end{tabular}

significant segment of stakeholders, representing the specific needs and motivations of visitors as regards to mobility.

The participating actors, located in different European countries, mainly in Mediterranean touristic urban areas, including Greece, belonged to six groups:

(a) Local Authorities (LAs),

(b) Transport Operators and Mobility Providers (TOs),

(c) Tourism Sector (TS),

(d) Academic Institutions (AI),

(e) Mobility Experts (ME), and

(f) Environmental Groups (EG). 


\subsection{Evaluation Table}

Based on extensive literature research and evaluation reports, the evaluation matrix was formed (Table 2). For the evaluation criteria, the values of the sustainable mobility alternative policies were ranked on a five-point scale.

\subsection{Weight Factors}

The selected criteria were evaluated in respect to their significance; their ranking provided the required data for the calculation of corresponding weights for the analysis. Each member of the panel completed a classification table, indicating their order of preference, from the most important criterion (1) to the least important (10). The relative weights were calculated for each response, while the weight of each criterion per stakeholder group was calculated as the average value of the relative weights of the actors in the specific group.

The mean weight of each criterion was calculated and the weights normalised, so that they become comparable (Tsoutsos et al., 2009).

\subsection{Sensitivity Analysis}

A sensitivity analysis was performed, using the tools of the Visual PROMETHEE software, such as "Walking Weights" that allows altering values of weight factors to observe their impact in the final classification and "Stability Intervals" that defines the alteration limits of weights inside which the final classification remains identical unchanged.

\section{Results}

\subsection{Calculation of the Weight Factors}

Following the aforementioned methodology per stakeholder group, relative weights (\%) for every group were calculated (Table 3).

\subsection{Ranking of the Alternative Policies Per Group}

In Table 4 are shown the high policy priorities according to the groups. 


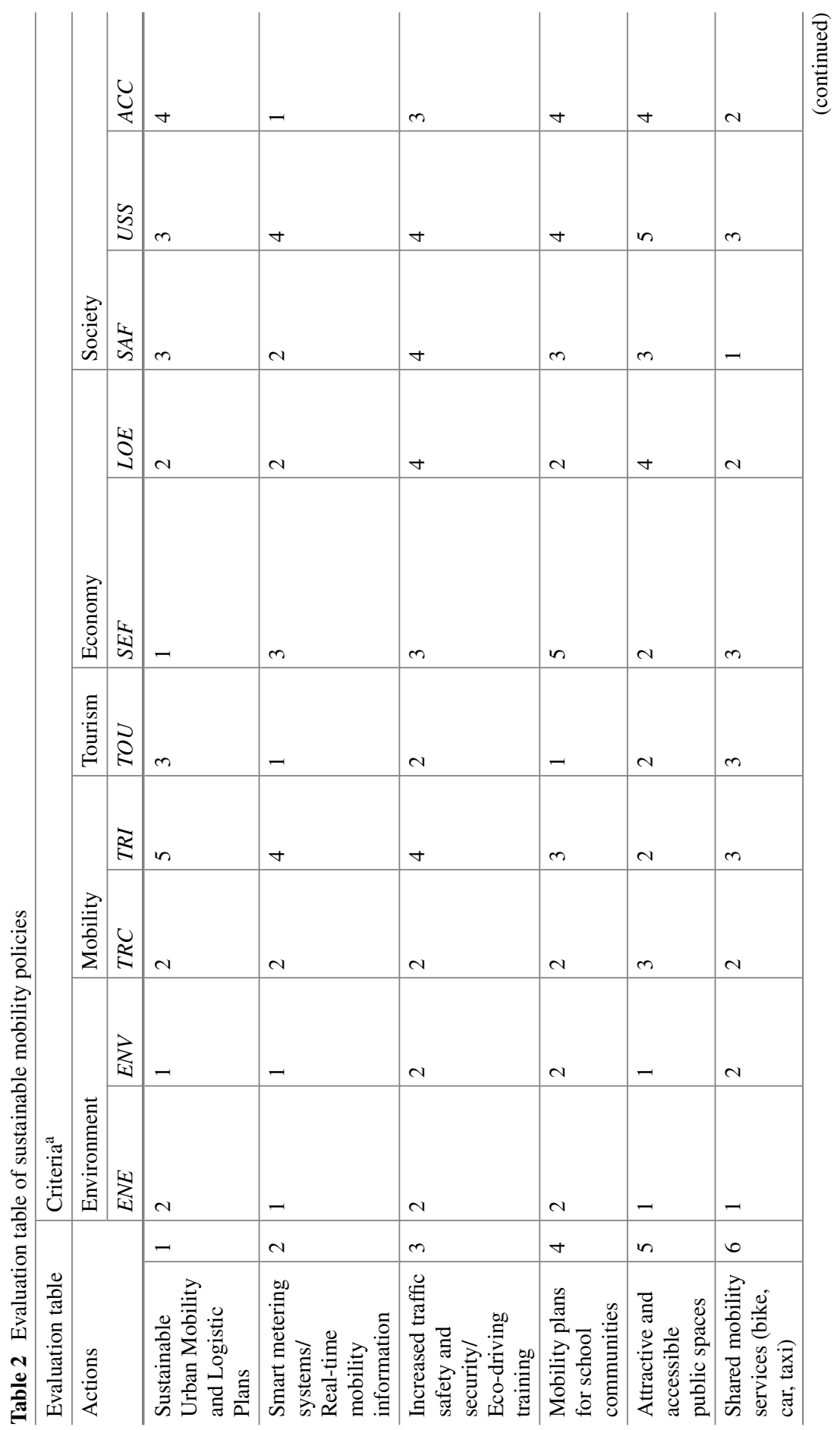




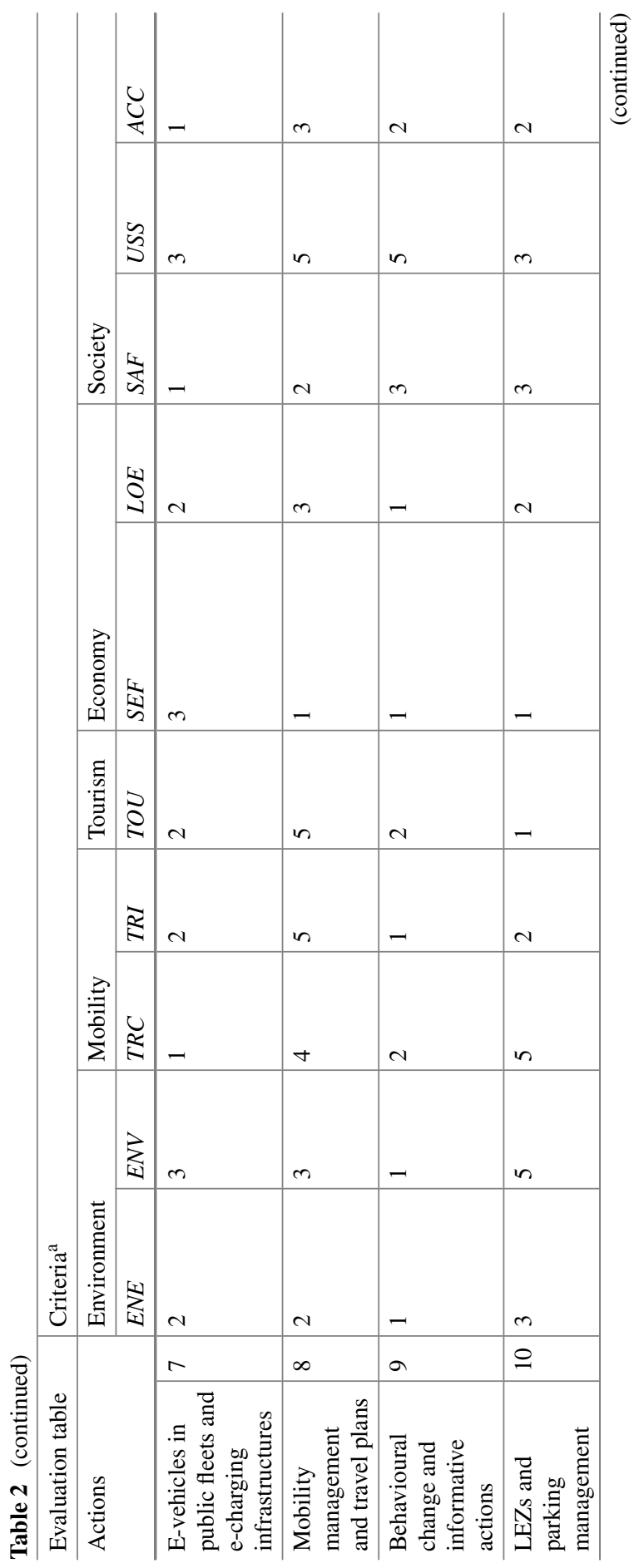




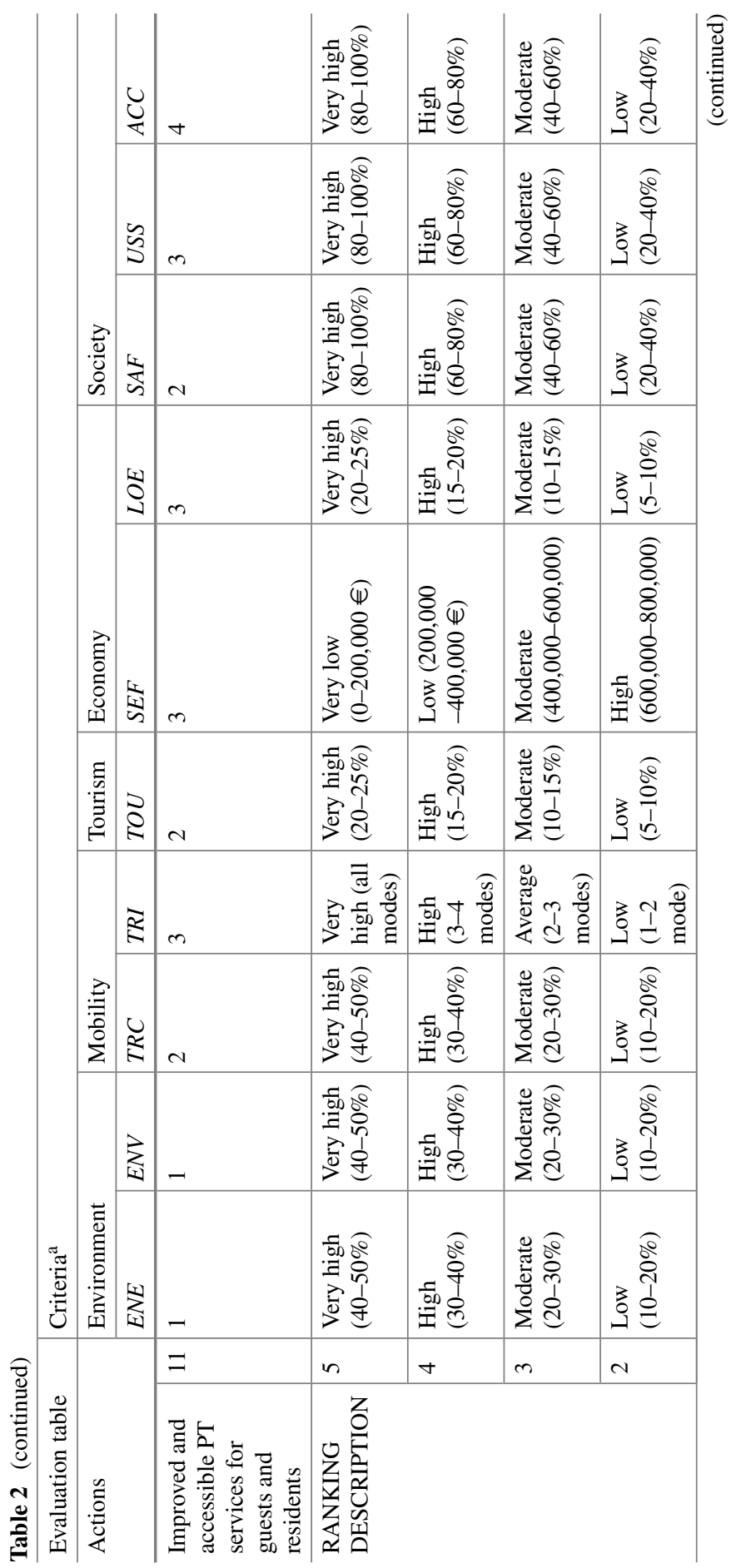




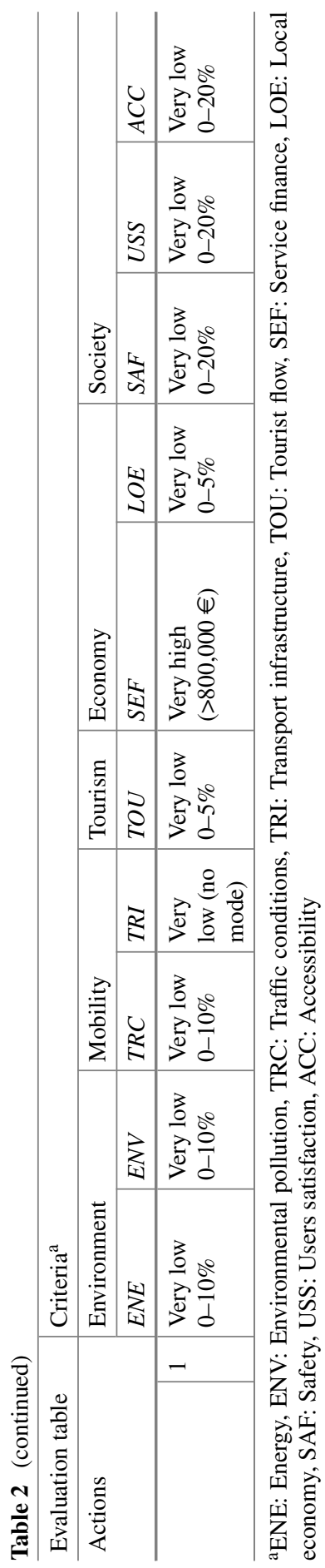


Table 3 Weights (\%) matrix for all stakeholder groups

\begin{tabular}{l|l|l|l|l|l|l|l|l|l|l}
\hline Group & ENE & ENV & TRC & TRI & TOU & SEF & LOE & SAF & USS & ACC \\
\hline $\begin{array}{l}\text { Local } \\
\begin{array}{l}\text { Authorities } \\
\text { (LA) }\end{array}\end{array}$ & 11.36 & 13.79 & 11.82 & 11.52 & 6.21 & 3.64 & $\mathbf{3 . 4 8}$ & 11.97 & 11.21 & $\mathbf{1 5 . 0 0}$ \\
\hline $\begin{array}{l}\text { Transport } \\
\text { Operators (TO) }\end{array}$ & 7.27 & 9.82 & $\mathbf{1 3 . 8 2}$ & 12.00 & 6.55 & 8.55 & 11.45 & 12.18 & $\mathbf{4 . 9 1}$ & 13.45 \\
\hline $\begin{array}{l}\text { Tourism Sector } \\
\text { (TS) }\end{array}$ & 15.76 & $\mathbf{1 6 . 9 7}$ & 8.79 & 10.30 & 9.70 & $\mathbf{3 . 9 4}$ & 7.58 & 9.70 & 6.36 & 10.91 \\
\hline $\begin{array}{l}\text { Academic } \\
\text { Institutions } \\
\text { (AI) }\end{array}$ & 6.36 & 15.00 & 11.36 & 7.73 & 7.27 & $\mathbf{4 . 0 9}$ & 10.91 & $\mathbf{1 5 . 4 5}$ & 9.09 & 12.73 \\
\hline $\begin{array}{l}\text { Mobility } \\
\text { Experts (ME) }\end{array}$ & 8.64 & 9.85 & 12.27 & 10.76 & 10.76 & $\mathbf{6 . 2 1}$ & 7.73 & 8.33 & 12.27 & $\mathbf{1 3 . 1 8}$ \\
\hline $\begin{array}{l}\text { Environmental } \\
\text { Groups (EG) }\end{array}$ & 14.55 & $\mathbf{1 7 . 5 8}$ & $\mathbf{5 . 4 5}$ & 10.91 & 6.06 & 10.00 & 6.97 & 11.52 & 6.67 & 10.30 \\
\hline
\end{tabular}

Local Authorities (LA): the accessibility criterion evaluated as the most important with $15.00 \%$, and the least important criteria were the economic ones

Transport Operators (TO): EU TOs showed a preference for technical and social criteria. The least important criterion was the tourist flow

Tourism Sector (TS): showed a preference for environmental criteria. The least important criteria were service finance (EU)

Academic Institutions (AI): the highest weight factor was safety; the least important is service finance

Mobility Experts (ME): EU MEs expressed a maximum preference for the accessibility criterion and the minimum for service finance

Environmental Groups (EG): EU EGs put greater emphasis on environmental criteria, giving the highest weight factors to environmental pollution and energy; the least important criterion was "traffic conditions" (5.45\%)

LA: Local Authorities, TO: Transport Operators/ Provides / Services, TS: Tourist Sector, AI: Academic Institutions, ME: Mobility Experts, EG: Environmental Groups

\subsection{Total Classification of Alternatives Solutions}

According to the results of the PROMETHEE II Complete Ranking for all stakeholder groups (Fig. 3), "Mobility management and travel plans" policy is classified as the most suitable policy, followed by "Increased traffic safety and security-Eco-driving training" and the "LEZs and parking management" as a second option.

The medium-ranked policies for EU groups by descending order are as follows: Sustainable Mobility Plans, Mobility plans for school communities, Attractive and accessible public spaces, Shared mobility services, Improved and accessible PT services for tourists and residents, and Behavioural change and informative 
Table 4 PROMETHEE II ranking for all EU stakeholder groups

\begin{tabular}{|c|c|c|c|c|c|c|c|}
\hline Ranking table & Stak & & & & & & Total \\
\hline Actions & $L A$ & TO & $T S$ & $A I$ & $M E$ & $E G$ & \\
\hline $\begin{array}{l}\text { Sustainable urban mobility } \\
\text { plans/sustainable urban } \\
\text { logistic plans }\end{array}$ & 4 & 4 & 4 & 6 & 4 & 5 & 4 \\
\hline $\begin{array}{l}\text { Smart metering } \\
\text { systems/real-time mobility } \\
\text { information }\end{array}$ & 10 & 9 & 9 & 10 & 10 & 9 & 10 \\
\hline $\begin{array}{l}\text { Increased traffic safety and } \\
\text { security—eco-driving } \\
\text { training }\end{array}$ & 2 & 2 & 2 & 2 & 2 & 2 & 2 \\
\hline $\begin{array}{l}\text { Mobility plans for school } \\
\text { communities }\end{array}$ & 5 & 5 & 5 & 5 & 6 & 4 & 5 \\
\hline $\begin{array}{l}\text { Attractive and accessible } \\
\text { public spaces }\end{array}$ & 6 & 6 & 7 & 4 & 5 & 7 & 6 \\
\hline $\begin{array}{l}\text { Shared mobility services } \\
\text { (bike, car, taxi) }\end{array}$ & 7 & 8 & 6 & 8 & 8 & 6 & 7 \\
\hline $\begin{array}{l}\text { E-charging infrastructures } \\
\text { and e-vehicles in public } \\
\text { fleets }\end{array}$ & 11 & 11 & 11 & 11 & 11 & 11 & 11 \\
\hline $\begin{array}{l}\text { Mobility management and } \\
\text { travel plans }\end{array}$ & 1 & 1 & 1 & 1 & 1 & 1 & 1 \\
\hline $\begin{array}{l}\text { Behavioural change and } \\
\text { informative actions }\end{array}$ & 9 & 10 & 10 & 9 & 9 & 10 & 9 \\
\hline $\begin{array}{l}\text { Low emission zones and } \\
\text { parking management }\end{array}$ & $3(3)$ & $3(3)$ & $3(3)$ & $3(3)$ & $3(6)$ & $3(3)$ & 3 \\
\hline $\begin{array}{l}\text { Improved and accessible PT } \\
\text { services for tourists and } \\
\text { residents }\end{array}$ & 8 & 7 & 8 & 7 & 7 & 8 & 8 \\
\hline
\end{tabular}

actions, while the second-worst policy was "Smart metering systems"; "E-charging infrastructures and e-vehicles in public fleets" policy was classified as the worst.

As observed, LA, TO, and TS present the exact same ranking for seven policies and slight differences for the remaining. The members of the groups AI, ME, and EG exhibit similarities between them and with the first three groups for 3-5 policies. 


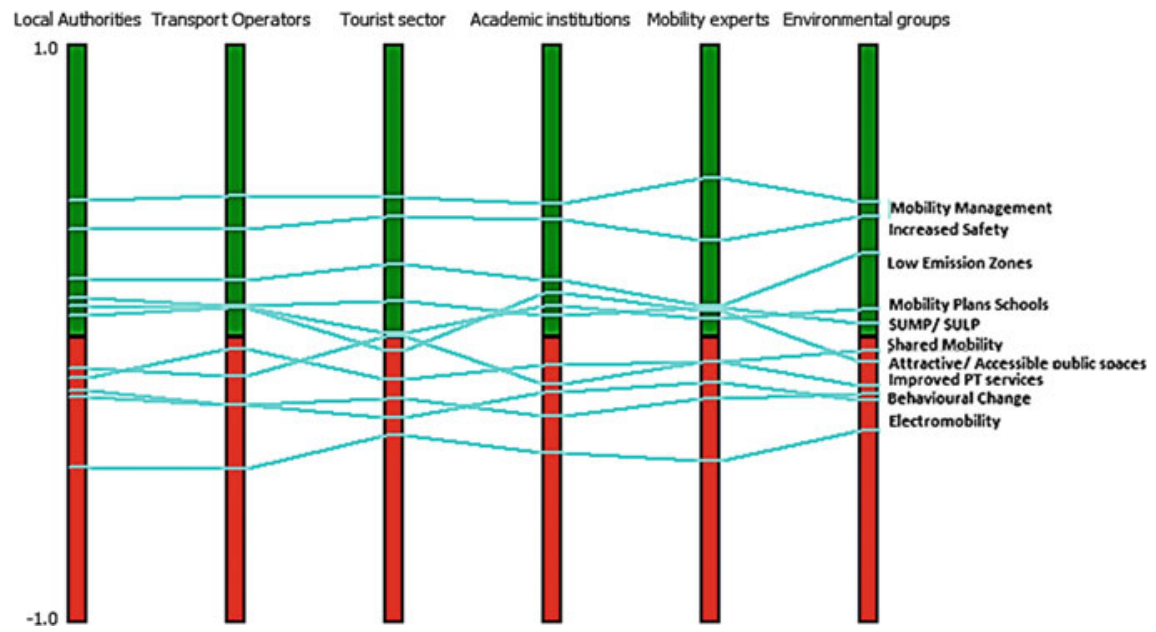

Fig. 3 Scenarios comparison PROMETHEE II ranking for all EU stakeholder groups

\section{Discussion}

\subsection{Scenarios Comparison}

Figures 2 and 3 depict the classification of PROMETHEE II for all stakeholder groups, comparing the different scenarios. Per group, vertical green and red lines are displayed (Phi+ $=1.0, \mathrm{Phi}-=-1$ ) and horizontal blue lines, representing each policy, cross the vertical lines, representing the value each action received, and attribute the net flow values (Phi) per criterion.

The "Mobility management and travel plans" policy was ranked as the most suitable amongst all groups, the "Increased traffic safety and security-Eco-driving training" policy as the second most proper, and the "E-charging infrastructures and e-vehicles in public fleets" as the worst one, due to their performance in highly weighted criteria (Fig. 3). It can be observed that the in-between ranking of the policies per group differs in a higher or lower degree.

\subsection{Sensitivity Analysis}

The abovementioned ranking of the sustainable mobility policies per group was finally determined by the weights given to the criteria; however, the weights' impact in the final classification is not clear. In order to identify whether the final ranking would change without the weight factors attributed, the "Walking weights" tool was used. Figure 4 presents the final ranking of the policies in case of equal weights, 

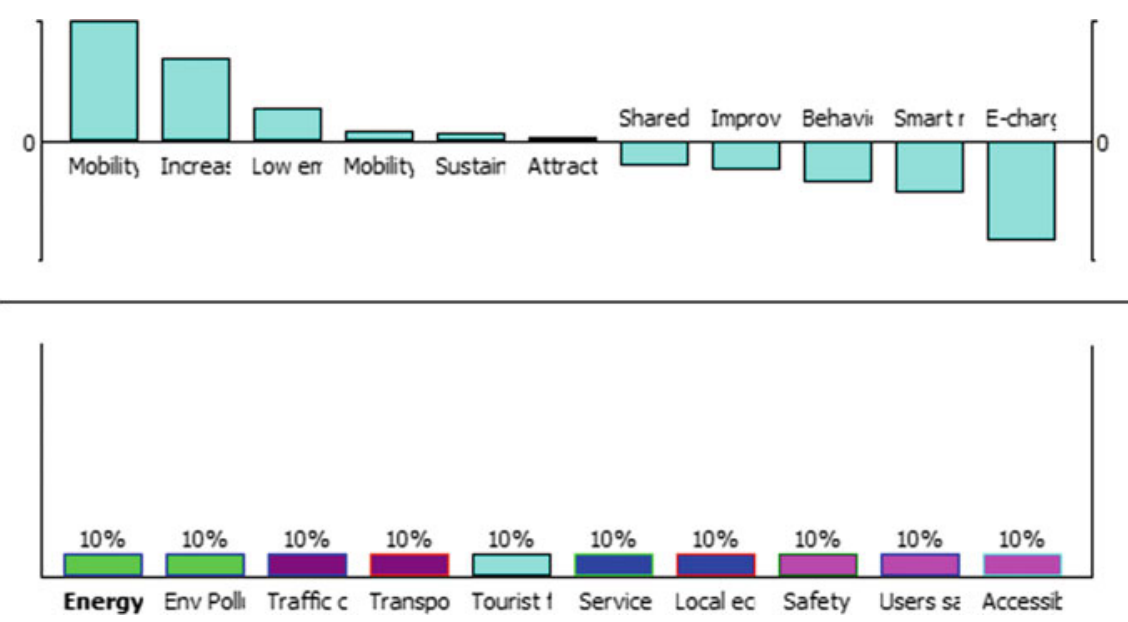

Fig. 4 Walking weights for sustainable mobility criteria

setting a $10 \%$ weight factor per criterion $(=100 \% / 10$ criteria $)$.

It can be observed that "Mobility management and travel plans" and "Increased traffic safety and security-Eco-driving training" policies remain at the top of the PROMETHEE II ranking, the "E-charging infrastructures and e-vehicles in public fleets" policy remains at the bottom, while the ranking of the remaining policies changes for some groups.

Additional tools for sensitivity analysis were applied, as provided by the Visual PROMETHEE software, to assess the interval stability of the criteria. The "stability intervals" per criterion present the alteration limits in relation to the calculated weights; this analysis can be applied to all policies in order to examine the potential alteration of the total ranking or it can even be applied to the top-ranked policies to examine their stability. The stability interval of the weights for "Mobility management and travel plans", in reference to the weights, was calculated. The minimum values do not exceed $1.36 \%$, while the maximum values of the weights range from $17.72 \%$ to $100 \%$. The stability intervals indicate that the top-ranked policy is very stable. At the same time, the criteria "Energy" and "Safety" are the most "sensitive" at both levels, since they have the lowest alteration limits, meaning that if the weights exceed the maximum value, the "Mobility management and travel plans" would no longer be the top-ranked policy.

\subsection{Identifying Stakeholders' Interests}

Despite the fact that weight factors do not drastically change the ranking of the policies, they can provide valuable insights into the interests of each stakeholder group. According to the results of this process, the priority criteria per group are 
Table 5 Priority and least important criteria for all groups

\begin{tabular}{l|l|l}
\hline Stakeholder group & $\begin{array}{l}\text { Highest priority criteria-EU } \\
\text { level }\end{array}$ & $\begin{array}{l}\text { Lowest important criteria-EU } \\
\text { level }\end{array}$ \\
\hline Local Authorities & $\begin{array}{l}\text { Accessibility, environmental } \\
\text { pollution }\end{array}$ & Service finance \\
\hline Transport Operators & Traffic conditions, accessibility & Tourist flow \\
\hline Tourist Sector & Environmental pollution, energy & Service finance \\
\hline Academic Institutions & Safety, environmental pollution & Service finance \\
\hline Mobility Experts & $\begin{array}{l}\text { Accessibility, traffic conditions, } \\
\text { users satisfaction }\end{array}$ & Service finance \\
\hline Environmental Groups & Environmental pollution, Energy & Traffic conditions \\
\hline Local Communities & - & - \\
\hline
\end{tabular}

listed in Table 5. It can be easily perceived that specific criteria have prevailed in the preferences of two or more groups, highlighting the interdependencies between groups' interests.

Most groups emphasise on at least two out of five criteria categories: Society and Environment or Society and Mobility, the most important criteria being Environmental pollution, Accessibility, Safety, Energy, and Traffic conditions.

Overall, two specific stakeholder groups present specific but anticipated priorities: EG gives priority strictly to environmental criteria, as expected, (Macharis et al., 2010, Lebeau et al., 2018, Bergqvist et al., 2015). However, TS also places the highest weights on environmental criteria (Michailidou et al., 2016), followed by social and tourism criteria, acknowledging the raised awareness on the links of tourism and environmental pollution (Abdul et al., 2017).

Amongst the least important criteria, service finance prevailed for most groups, indicating that economic demands would not determine the implementation of a potential mobility policy.

Overall, most groups give priority to criteria related to the wellbeing of local communities and the quality of life, despite the economic implications of services and the potential impact on incoming tourism.

\section{Conclusions and Recommendations}

This chapter aimed to assess 11 sustainable urban mobility policies for European medium-sized touristic cities in the Mediterranean region, integrating stakeholders' viewpoint through MCDA, more specifically with the use of the PROMETHEE model. As an added value, the study incorporated (a) the tourism aspects in various steps of the analysis and (b) a two-level stakeholder involvement approach and comparison of European and local stakeholders' interests and results. 
The study revealed that most stakeholders give priority to the wellbeing of local communities and the quality of life, despite the economic implications of services and the potential impact on incoming tourism. Most EU groups emphasise on at least two out of five criteria categories: Society and Environment or Society and Mobility. Interestingly, the Tourism Sector group expressed a preference for environmental criteria, demonstrating the continuously raising awareness on the links of tourism and environment.

Overall, environmental pollution, accessibility, safety, energy, and traffic conditions were identified as the most important criteria. Service finance prevailed as the least important for most EU level groups.

For all groups, "Mobility management and travel plans" policy was classified as the most popular policy, indicating that the provision of information, personalised plans, and smart applications can increase the use of sustainable mobility modes and have a significant positive impact on all examined categories. On the other hand, the "E-charging infrastructures and e-vehicles in public fleets" policy was classified for all groups as the worst option, and despite being considered the "green" alternative to conventional vehicles, this policy doesn't have significant impacts on all aspects examined.

The analysis ranked and identified the optimal sustainable mobility policies, based on their overall performance to the weighted criteria. However, when the three topranked policies were further analysed according to their performance on priority criteria, it was found that although they present a good overall performance, one may overcome the other on specific criteria. Having this in mind, it can be assumed that the ranking consists of a suggestion and the final selection by a decision-maker can be different, according to targeted needs.

The incorporation of stakeholders' viewpoint is essential for an integrated approach and under this principle, this study took place, proposing the optimal solution for each stakeholder group according to their preferences. Nevertheless, the study could be further enhanced by the inclusion of a higher number of participating stakeholders, in order to have an even more representative sample of actors; especially the inclusion of local communities and users at the EU level would make the comparison of the two levels feasible.

Further research could include the addition of a time-related criterion, aiming to evaluate the preparation and implementation period per policy required to present potential impact and, in this way, identify short-term and long-term policies that might be more suitable according to the specific areas. On the other hand, the financial criteria could be omitted from the assessment, since-according to the results - they were considered of less significance. Nonetheless, if required, they can be further examined through a cost-benefit analysis. In cases where external funding sources are available, financial implications are less concerning for local authorities.

Further, the enhancement of the evaluation matrix with existing data related to a particular city/area or with real data collected/monitored in the city will strengthen the analysis, increasing the precision of the results and thus facilitating the shaping of future local policy. In addition, it would be particularly interesting for decisionmakers to assess different sustainable mobility policies under the same thematic area 
(e.g. different safety policies or various smart metering systems), in case a specific area of intervention is already identified, or even proceed to such approach as a "second" stage analysis, following the suggestions of the initial analysis.

In terms of participation, the tourism sector and the local communities were particularly "difficult" teams to involve, a fact indicating the lack of awareness and/or active engagement and participation in mobility planning processes. Speedy answers were provided by academic institutions and mobility experts ( 29 answers). The necessary data gathering for the evaluation matrix fulfilment was faced by the selection of suitable data from already demonstration projects and relevant publications in order to achieve a high-quality and reliable estimation of performance.

As an overall conclusion, the multi-criteria analysis performed in this study can be a valuable tool for decision-makers during the shaping of future policies for sustainable mobility in urban tourist destinations, considering numerous parameters and stakeholders' viewpoints, but it can be further developed and adapted to specific needs.

\section{References}

Abdul, S., Khan, R., Qianli, D., Songbo, W., Zaman, K, \& Zhang, Y. (2017). Travel and tourism competitiveness index : The impact of air transportation, railways transportation, travel and transport services on international inbound and outbound tourism. Journal of Air Transport Management, 58, 125-134.

Aguiló, E., Palmer, T., \& Rosselló, J. (2012). Road transport for tourism: Evaluating policy measures from consumer profiles. Tourism Economics, 18(2), 281-293.

Awasthi, A., Omrani, H., \& Gerber, P. (2018). Investigating ideal-solution based multicriteria decision making techniques for sustainability evaluation of urban mobility projects. Transportation Research Part A: Policy and Practice, 116, 247-259.

Bergqvist, R., Macharis, C., Meers, D., \& Woxenius, J. (2015). Making hinterland transport more sustainable a multi actor multi criteria analysis. Research in Transportation Business \& Management, 14, 80-89.

Bulckaen, J., Keseru, I., Donovan, C., Davies, H., \& Macharis, C. (2015). Development of a new evaluation framework for urban and regional mobility projects. In Benelux interuniversity association of transport researchers: transportation research days 2015.

European Platform on Sustainable Urban Mobility Plans. (2019). Guidelines for developing and implementing a sustainable urban mobility plan (Second Edition). Accessed April 2020, from https://www.eltis.org/sites/default/files/guidelines_for_developing_and_implement ing_a_sustainable_urban_mobility_plan_2nd_edition.pdf

Gronau, W. (2017). On the move: Emerging fields of transport research in urban tourism. In Tourism in the city (pp. 81-91). Springer, Cham.

Lebeau, P., Macharis, C., Van Mierlo, J., \& Janjevic, M. (2018). Improving policy support in city logistics: The contributions of a multi-actor multi-criteria analysis. Case Studies on Transport Policy, 6(4), 554-563.

Letnik, T., Luppino, G., \& Bardi, A. (2018). Review of policies and measures for sustainable and energy efficient urban transport. Energy, 163, 245-257.

Macharis, C., De Witte, A., \& Turcksin, L. (2010). The multi-actor multi-criteria analysis (MAMCA) application in the Flemish long-term decision making process on mobility and logistics. Transport Policy, 17(5), 303-311. 
Michailidou, A. V., Vlachokostas, C., \& Moussiopoulos, N. (2016). Interactions between climate change and the tourism sector: Multiple-criteria decision analysis to assess mitigation and adaptation options in tourism areas. Tourism Management, 55, 1-12.

Page, S., \& Gue, Y. (2016). Transportation and tourism: A symbiotic relationship. In T. Jamal \& M. Robinson (Eds.), The Sage Handbook of Tourism. Sage Publications.

Saenz-de-Miera, O., \& Rosselló, J. (2012). The responsibility of tourism in traffic congestion and hyper-congestion: A case study from Mallorca, Spain. Tourism Management, 33(2), 466-479.

Sun, H., Zhang, Y., Wang, Y., Li, L., \& Sheng, Y. (2015). A social stakeholder support assessment of low-carbon transport policy based on multi-actor multi-criteria analysis: The case of Tianjin. Transport Policy, 41, 103-116.

Tsoutsos, T., Drandaki, M., Frantzeskaki, N., Iosifidis, E., \& Kiosses, I. (2009). Sustainable energy planning by using multi-criteria analysis application in the island of Crete. Energy Policy, 37(5), $1587-1600$.

Open Access This chapter is licensed under the terms of the Creative Commons Attribution 4.0 International License (http://creativecommons.org/licenses/by/4.0/), which permits use, sharing, adaptation, distribution and reproduction in any medium or format, as long as you give appropriate credit to the original author(s) and the source, provide a link to the Creative Commons license and indicate if changes were made.

The images or other third party material in this chapter are included in the chapter's Creative Commons license, unless indicated otherwise in a credit line to the material. If material is not included in the chapter's Creative Commons license and your intended use is not permitted by statutory regulation or exceeds the permitted use, you will need to obtain permission directly from the copyright holder. 